\title{
The Anaesthetic Technique of Choice among Pregnant Women fo r Caesarean Section in a Tertiary Health Centre
}

\author{
Adamu Sadiq Abubakar, ${ }^{1}$ Aliyu Usman El-Nafaty, ${ }^{2}$ Yusuf Sambo Tanimu. ${ }^{3}$ \\ Department of Anaesthesia and Intensive Care, University of Maiduguri Teaching Hospital, Maiduguri, ${ }^{l}$ Depar \\ tment of Obstetrics and Gynaecology, University of Maiduguri Teaching Hospital, Maiduguri, ${ }^{2}$ Department of A \\ naesthesia, Federal Teaching Hospital, Gombe. ${ }^{3}$
}

\begin{abstract}
:
Objective: This study is to ascertain the preferred choice of anaesthetic technique and their reasons, among pre gnant women schedule for caesarean section during preoperative visit in Federal Teaching Hospital, Gombe.

Methodology: This was a three year prospective study [from June, 2010-May, 2013] of pregnant women sched uled for either elective or emergency caesarean section. During the preoperative visit, patients were counselled and consent obtained on either regional or general anaesthesia and their reasons for the choice documented.

Results: A total of 1,350 women were interviewed during the three years period of the study.]The total of four $h$ undred and sixty one patients ( $n=461,34.1 \%)$ were scheduled for emergency caesarean section, while eight hun dred and eighty nine patients $(n=889,65.9 \%)$ were scheduled for an elective caesarean sections. They were age $d$ 17-40 years with the mean age of 27.84+/-4.43 years. The parity ranged from 1-12. Majority of the patients 9 45 (70\%) preferred regional anaesthesia, while $405(30 \%)$ preferred general anaesthesia The common reasons $f$ or their preference to regional anaesthesia include early contact with their babies, fear of death from general a naesthesia, want to know what is going on in the theatre, general anaesthesia is more dangerous, patient being awake, reduced blood loss, cheaper and well tolerated however, others preferred general anaesthesia because $o$ $f$ fears of the complications of regional anaesthesia e.g. backache, headache etc.

Conclusion: We conclude that regional anaesthesia is the preferred technique of choice for most pregnant wom en undergoing caesarean sections in our centre. Detail preoperative review with emphases on counselling of the patients by the anaesthetists on the advantages of regional anaesthesia over the general anaesthesia will encou rage the high preference of regional over general anaesthesia. We therefore, recommend that preoperative revie $w$ should be encouraged in all hospitals and in all patients undergoing either emergency or elective caesarean $s$ ections.
\end{abstract}

Key words: Choice of anaesthesia, pregnant women, Caesarean sections

\section{Introduction:}

Most caesarean sections were previously performed under general anaesthesia but there has been an inc reasing trend worldwide to the use of regional anaesthesia for caesarean deliveries. ${ }^{1}$ The reason for this shifts are not far-fetched and may not be unconnected to the complications of general anaesthesia such as difficult airway , regurgitation and aspirations, and hypoxaemia, which constitutes significance causes of maternal morbidity an $\mathrm{d}$ mortality. ${ }^{2} \quad$ The renewed interest in regional anaesthesia in obstetrics has led to its routine use for caesarean section. Small, non-cutting needles have decreased the incidence of post- dural puncture headache making regio nal anaesthesia acceptable in this population. The advantages of regional anaesthesia particularly the spinal anae sthesia include rapid onset of action, low local anaesthetic doses and good quality; and reliability of the block. ${ }^{3}$

The choice of anaesthetic techniques is guided by the maternal factors, indications for surgery, intercurr ent medical diseases, anaesthetist's preferences and equally important is the patient choice. Regional anaesthesia increases maternal satisfaction and bonding between mother and her newborn infant, ${ }^{4}$ and it is also associated $\mathrm{w}$ ith shorter hospital stay. ${ }^{5}$ Currently, general anaesthesia is usually reserved for caesarean deliveries when region al anaesthesia is absolutely contraindicated. ${ }^{6}$

There are absolute and relative contraindications to regional anaesthesia. The absolute contraindication $s$ includes infection at the site of injections, hypovolaemia, indeterminate neurologic diseases, coagulopathy, inc reased intracranial pressure and equally important is the patient refusal. ${ }^{7}$ Therefore, since patient refusal is an ab solute contraindication, we therefore, documented the choice of anaesthesia and the reasons of their choice follo wing detailed counselling during the preoperative visit within the study period.

\section{Patients And Methods:}

This is a prospective cross-sectional questionnaire based study on the consent taken on the pregnant wo men undergoing caesarean delivery and the reasons for their preferred choice in our centre. Questionnaires were filled after detail counselling on the technique of anaesthesia and signed consent on either regional or general an 
aesthesia was obtained. No participant declined participation in the study. Respondent were told that with region al anaesthesia they will be awake without feeling pains; they will see their babies immediately after delivery. Ot her relevant information obtained include, history of previous caesarean sections, types of anaesthesia during the previous caesarean section, preference for either regional or general anaesthesia and the reasons for the choice o $\mathrm{f}$ anaesthetic technique. The research and ethical committee of the hospital approved the study. The results are $\mathrm{p}$ resented as frequency and percentages. The association between clinical variables and anaesthetic services were tested using Chi square test. The level of significance is set at a probability of 0.05

\section{Results:}

A total of 1,350 respondents were interviewed during the three years' period of the study. The socio-de mographic characteristics of the patients are as shown in Table 1. The age range was 17-40 years, with a mean o f $27.84+/-4.43$ years. The parity ranged from 1-9 with the parity of 2-4 constituting $65.6 \%(\mathrm{n}=886)$ of the patien ts. Five hundred and sixty four of the patients $(41.8 \%$ ) had at least secondary education while $13 \%$ were illiterat es. Housewives $(n=713,52.8 \%)$ and Muslim $(n=918,68 \%)$ constituted the majority of the patients. Those havi ng surgery for the first time were $767(56.8 \%)$, while those for repeat caesarean section were $583(43.2 \%)$.

Table1: Socio-demographic characteristics of the patients interviewed $(n=1350)$

\begin{tabular}{|c|c|c|c|}
\hline Characteristics & & & \\
\hline \multicolumn{4}{|l|}{ Age (years) } \\
\hline$<20$ & 664 & 49.2 & \\
\hline $20-24$ & 253 & 18.7 & \\
\hline $25-29$ & 154 & 11.4 & \\
\hline 30- 34 & 123 & 9.1 & \\
\hline $35-39$ & 94 & 7.0 & \\
\hline$>40$ & 62 & 4.6 & \\
\hline Total: & 1350 & & 100 \\
\hline \multicolumn{4}{|l|}{ Parity } \\
\hline 1 & 254 & 18.8 & \\
\hline $2-4$ & 886 & 65.6 & \\
\hline$>5$ & 210 & 15.6 & \\
\hline Total & 1350 & & 100 \\
\hline \multicolumn{4}{|l|}{ Marital status } \\
\hline Married & 1332 & 98.7 & \\
\hline Single & 18 & 1.3 & \\
\hline Total: & 1350 & & 100 \\
\hline \multicolumn{4}{|l|}{ Educational status } \\
\hline Primary & 456 & 33.8 & \\
\hline Secondary & 564 & 41.8 & \\
\hline Tertiary & 154 & 11.4 & \\
\hline Illiterate & 176 & 13.0 & \\
\hline Total: & 1350 & & 100 \\
\hline \multicolumn{4}{|l|}{ Occupation } \\
\hline House wife & 713 & 52.8 & \\
\hline Business woman & 56 & 4.1 & \\
\hline Civil servant & 152 & 11.3 & \\
\hline Applicant & 226 & 16.7 & \\
\hline Student & 203 & 15.1 & \\
\hline Total: & 1350 & & 1 \\
\hline \multicolumn{4}{|l|}{ Religion } \\
\hline Moslem & 918 & 68 & \\
\hline Christian & 432 & 32 & \\
\hline Total: & 1350 & & 100 \\
\hline \multicolumn{4}{|c|}{ Previous caesarean section } \\
\hline Yes & 583 & 43.2 & \\
\hline NO & 767 & 56.8 & \\
\hline Total: & 1350 & 100 & \\
\hline
\end{tabular}

Table II details the anaesthetic preferences and the reasons proffered for the choice of anaesthesia. Maj ority of the patients $(n=945,70 \%)$ preferred regional anaesthesia and the remaining $(n=405,30 \%)$ preferred gen eral anaesthesia. The commonest reason for regional anaesthesia preference was the ability to see their babies im mediately after the surgery and the commonest reason of preference of general anaesthesia was fear of being aw 
ake. However, some patient gave multiple reasons for their choice.

Table II: Anaesthetic of choice and reasons proffered $(n=1350)$

Variables n

\begin{tabular}{lll}
\hline Regional anaesthesia (RA) & $\mathbf{9 4 5}$ & $\mathbf{7 0}$ \\
Reasons for preference for RA & & 26.7 \\
Want to see baby immediately & 252 & 11.9 \\
Fear of not waking up from GA & 112 & 11.1 \\
GA more dangerous & 105 & 8.2 \\
Want to see what is happening in theatre & 78 & 7.3 \\
Cost & 69 & \\
& & $\mathbf{3 0}$ \\
General anaesthesia (GA) & $\mathbf{4 0 5}$ & \\
& & 32.6 \\
Reasons for preference for GA & 132 & 19.3 \\
Fear of being awake & 78 & 15.3 \\
Anxiety & 62 & 19.3 \\
Want to be asleep & 78 & 22.7 \\
Do not want to be feel pain & 92 & 17.5 \\
Do not want to see the theatre & 71 & 9.5 \\
Fear of nightmare & 128 & 20 \\
No reason [Don't now] & 270 & \\
Give me the best & & \\
$\quad$
\end{tabular}

The relationship between some demographic characteristics and choice of anaesthetic technique are sho wn in Table III. Parity $\left(X^{2}=60.3, \mathrm{P}=0.00\right)$, Education $\left(X^{2}=1.93, \mathrm{P}=0.00\right)$ and Occupation $\left(X^{2}=22.13, \mathrm{P}=0.00\right)$ were significantly associated with the preference for regional anaesthesia, while Age $\left(X^{2}=3.53, \mathrm{P}=0.06\right)$, Religi on $\left(X^{2}=0.00, P=0.99\right)$ and Previous Caesarean section $\left(X^{2}=0.16, P=0.69\right)$ had no significant influence on pref erence of one form of anaesthetic technique over the other. Of the total of five hundred and eighty three patients $(\mathrm{n}=583)$ that had previous caesarean section delivery, three hundred and eighty seven $(\mathrm{n}=387,66.4 \%)$ prefer to $\mathrm{h}$ ave regional anaesthesia as a technique of choice and one hundred and ninety six $(n=196,33.6 \%)$ prefer to have general anaesthesia.

Table III: Relationship between some socio-demographic parameters and the choice of anaesthetic techni que.

Types of Anaesthesia

RA GA TOTAL

$\operatorname{Ages}(\mathbf{y r s})$
$<20$

71

25- 29

30- 34

$35-39$

$>40$

Total

$X^{2}=3.53, \mathrm{P}=0.06$

Parity

1

20- 24

253
443

107

102

69

42

945

184
221

664

182

154

123

94

62

1350 
2- 4

$>5$

0

Total

$X^{2}=60.3, \mathrm{P}=0.000$

Educational status

Primary

6

Secondary

4

Tertiary

4

Non-literate

Total

50

$X^{2}=1.93, \mathrm{P}=0.00$

Occupation

House wife

Business woman

Civil servant

52

Student

03

Applicant

226

335

$X^{2}=22.13, \mathrm{P}=0.00$

\section{Religion}

Moslem

918

114

Total

1350

$X^{2}=0.00, \mathrm{P}=0.99$

Previous caesarean section

Yes

583

NO

767

Total

1350

$X^{2}=1.26, \mathrm{P}=0.26$
667

120

219

90

379

1350

169

45

424

140

56

86

68

15

89

886

87

176

464

13

582

131

713

32

24

56

96

56

1

141

62

164

62

Total

1350

1015

Christian

432

676

242

318

356

196

476

291

863

487

\section{Discussion:}

This study show high preference of regional anaesthesia of $70 \%$ of our respondents over general anaest hesia during preoperative visit which defer with the study reported by Bukar, et al ${ }^{8}$ from a tertiary centre in the $\mathrm{s}$ ame region of only $29.9 \%$ that prefer regional anaesthesia over general anaesthesia among ante-natal attendees. They advocated the low preference on regional anaesthesia to lack of access to information regarding the types o $\mathrm{f}$ anaesthetic techniques and lack of anaesthetic manpower in their centre. Their study was done among pregnant women during antenatal visit while ours was during preoperative visit. However, in our study the high preferen ce for regional anaesthesia may be as a result of access to information regarding the types of anaesthetic techniq ue during preoperative visit which is compulsory, where counselling is done before consent was taken. Our cen tre also has more of the anaesthetic manpower.

Recent studies have shown that both general and regional anaesthesia are safe but regional anaesthesia gives better maternal and foetal outcomes ${ }^{9}$ Moreover, in a study by Van Houwe et al ${ }^{10}$ reported as high as $80 \%$ of pregnant women preferred regional anaesthesia, the reason was due to easy accessibility of information on an aesthesia technique which is in an agreement with our findings. However, in the study by Imarengiaye, et al the 
y reported only $43 \%$ use of regional anaesthesia in obstetrics patients for caesarean sections.

Reports indicate similar trend with the growth of regional anaesthesia for caesarean section in the Unit ed State of America. Hawkins, et at ${ }^{12}$ showed that for caesarean section, general anaesthesia decreased from 35 $\%$ in 1981 to $12 \%$ in 1992 for hospital with over 1500 deliveries per annum, and from $46 \%$ to $22 \%$ in hospital w ith annual delivery rate of over 500. These changes parallel the development of obstetric anaesthesia as a sub-sp ecialty. It is likely that the use of regional anaesthesia for caesarean section in our hospital may improve further as the obstetric anaesthesia unit gains foothold.

Various reasons were proffered for preference of one anaesthetic technique over the other. The commonest reason is the advantage of seeing their babies immediately after the delivery and the fear of the complications of general anaesthesia , however, significant number said "Give me your best" which entails that regional anaesthesia is preferred. The majority of $\mathrm{t}$ hose who preferred general anaesthesia did so because of the fear of being awake but with proper counselling to allay their fear the consent for regional anaesthesia will improve. Fear of death under general anaesthesia was th e leading concern for those undergoing anaesthesia in previous studies. ${ }^{13}$ however, only $11.9 \%$ of our responden ts thought that death under general anaesthesia was the reason for the preference of regional anaesthesia.

In conclusion, regional anaesthesia is safer and the most preferred over general anaesthesia among pre gnant women for caesarean section in our centre. It is recommended that regular preoperative visits should be co nducted by anaesthesiologists, proper and detail counselling of pregnant women on various anaesthetic techniqu es during such visits will significantly improve patient consent for regional anaesthesia for caesarean sections in developing countries.

Conflict of interest: no financial assistance

\section{References:}

[1]. Crawford-Sylkes A, Scarlet M, Hambleton K, Rottray C. Anaesthesia for operative deliveries at University hospital of the West indies: a change of practices. West Indian Med J 2005; 54: 187-91.

[2]. Adeleye JA. Maternal mortality and caesarean section at the UCH, Ibadan. Trop J Obstet Gynecol 2005; $106: 281-7$.

[3]. Afolabi BB, Lesi FE, Merch WA. Regional versus general anaesthesia for caesarean section. Cochrane Database systematic Review 2006; 18: CD 004350.

[4]. Amata AO. Anaesthesia for caesarean section in some tertiary obstetrics units in Nigeria- A pilot study. Nigerian postgraduate medical journal 1998; 28: 2-5.

[5]. Fassouliki A, Petropoulos G, Staikous C, Sinfaka I, Sarantopoulos. General versus neuraxial anaesthesia for caesarean section: impact on the duration of hospital stay. Journal of obstetrics and Gynaecology 2009; 29: 25-30.

[6]. Morgan BM, Magni V, Goroszenuik T. Anaesthesia for emergency caesarean section. Br J obstet Gynaecol 1990; 97: 420-4

[7]. Imarengiaye CO, Ande AB, Obiaya MO. Trends in regional anaesthesia for caesarean section at University of Benin Teaching Hospital. Nig J Clinical practice 2001; 4: 15-18.

[8]. Bukar M, Kwari DY, Moruya JY, Ndonya DN. Anaesthesia for caesarean delivery: Choice of Anaesthetic technique among antenatal attendees in North-eastern Nigeria. Journal of obstetrics and Gynaecology 2010; 30(8): 622-5.

[9]. Martins TC, Bell P, Ogunbiyi O. Comparison of general anaesthesia and spinal anaesthesia for caesarean section in Antigua and Barbuda. West Indian Journal 2007; 56: 330-3.

[10]. Van Houwe P, Heyterans L, Vercruysse. A survey of obstetrics anaesthesia practices in Flanders. Acta Anaesthesiologica Belgica 2006; $2: 170-6$.

[11]. Imarengiaye Charles, Adamu Sadiq Abubakar. Audit of clinical services in an obstetrics anaesthesia unit in a tertiary teaching hospital. Journal of Biomedical Sciences 2005; 4(2): 29-33.

[12]. Hawkins JL, Gibbs CP, Orleans M. Obstetrics anaesthesia workforce survey: 1981 versus 1992. Anesthesiology 1997; 87: $135-143$.

[13]. Lewis G. The seventh Report on Confidential Enquiries into Maternal Deaths in the United Kingdom, 2003-2005. London 2007; CEMACH. 